\title{
In vitro estimation of superfluid critical extracts of some plants for their antimicrobial potential, phytochemistry, and GC-MS analyses
}

Waleed Bakry Suleiman ${ }^{1,2^{*}}$

\begin{abstract}
Background: Along with swift economic evolution and continuous amelioration of lifestyle, people at present are paying more attention to health issues. Synthetic drugs will be compensated with other natural ones that belong to natural origin. Plants have always been considered as sources of several compounds that are used in many fields, especially human and animal health, starting from boosting immunity to the treatment of infectious diseases caused by some pathogenic microbes such as bacteria, fungi as well as viruses. This study aimed to incorporate some types of plants within the antimicrobial portfolio through the examination of different six plants which were Cichorium intybus, Cinnamomum camphora, Commiphora myrrha, Foeniculum vulgare, Nerium oleander, and Spartium junceum. As well, attempting to identify the active constituents of their extracts using GC-MS.
\end{abstract}

Materials and methods: All selected plants were analyzed to determine their phytochemical composition such as phenolics, alkaloids, flavonoids, terpenoids, and so on. The extraction step was done by sophisticated equipment called supercritical fluid extractor SFE through adjustment of specific conditions include temperature, time, flow rate and pressure to change the behavior of $\mathrm{CO}_{2}$. Testing the antimicrobial activity of each plant extract via agar well diffusion method through the formation of clear zones against a wide range of test microorganisms including both Gram-positive and Gram-negative bacteria as well as yeasts. Finally, attempting to primarily identify the constituents of each plant extract using GC-MS.

Results and discussion: The crude extract of F. vulgare showed the highest potency against C. albicans, E. faecalis and S. typhimurium, it contains some unique compounds such as squalene, eugenol and isoeugenol while, Extract of C. intybus showed a moderate activity especially against C. lipolytica and MRSA and it includes Vitamin A like compound which indicates antioxidant property.

Conclusion: Conclusively, fennel gave a promising result as a good wide spectrum antimicrobial agent because it contains some compounds act as antimicrobial agents such as eugenol which was used as food preservatives in addition to squalene which acts as an antioxidant and antimycotic agent so, it will be useful especially while it was used in highly purified form excluding all undesirable subcomponents.

Keywords: Phytochemistry, GC-MS, SFE, Cichorium, Cinnamomum, Commiphora, Foeniculum, Nerium, Spartium, Antimicrobial

\footnotetext{
*Correspondence: drwbs@kumamoto-u.ac.jp

${ }^{1}$ Department of Botany and Microbiology, Faculty of Science, Al-Azhar University, The Permanent Camp St., 6th Ward, P.B. 13759, Nasr City, Cairo, Egypt

Full list of author information is available at the end of the article
}

\section{Background}

The majority of microorganisms are free-living and perform useful activities however, some microorganisms caused diseases are called pathogens. They include bacteria, viruses, fungi, and protozoa. Infection occurs

c) The Author(s) 2020. This article is licensed under a Creative Commons Attribution 4.0 International License, which permits use, sharing, adaptation, distribution and reproduction in any medium or format, as long as you give appropriate credit to the original author(s) and the source, provide a link to the Creative Commons licence, and indicate if changes were made. The images or other third party material in this article are included in the article's Creative Commons licence, unless indicated otherwise in a credit line to the material. If material is not included in the article's Creative Commons licence and your intended use is not permitted by statutory regulation or exceeds the permitted use, you will need to obtain permission directly from the copyright holder. To view a copy of this licence, visit http://creativeco mmons.org/licenses/by/4.0/. The Creative Commons Public Domain Dedication waiver (http://creativecommons.org/publicdomain/ zero/1.0/) applies to the data made available in this article, unless otherwise stated in a credit line to the data. 
when a pathogen invades a body that resulted in clinical infection, such an infection is referred to as subclinical asymptomatic disease [1]. Microbial infections are most frequently caused by the resident microflora of the host rather than by exogenous invaders. Generally, harmless microorganisms may become virulent due to changes in the host's tolerance or an alteration in the host's microbial flora because of antibiotic use [2]. Antimicrobials reduced the morbidity and ameliorate human health against microbial infections. The incidence of antimicrobial resistance is increasing among all types of patients. Not all infections require specific antimicrobial treatment and careful clinical judgment is essential to determine whether symptomatic treatment is enough. Microbiological investigations should always be carried out before treatment [3]. Excessive use of antibiotics without advice of physicians, non-adjusted course of the antibiotic or uncompleted dosage, unsuitable antibiotic administration; all of these are the reason for bacterial resistance. Physicians should request a report of bacterial culture sensitivity (leastwise, as a phenotypic method) in cases of bacterial infection to detect the suitable antibiotic. Most of the Staphylococcus aureus isolates became MRSA (methicillin-resistant S. aureus), some of them became VRSA (vancomycin-resistant S. aureus), that means the scientists should act more and more to incorporate either more generations of antibiotics or new categories of antibiotics especially those belong to natural origin like plants, mushroom, truffles [4]. The use of plants in the pharmacological treatment of disease began long ago [5]. Centuries ago, Chinese, Japanese, and Indian used herbs in disease treatment as traditional medicine [6, 7]. In Europe and North America; herbal products have been expanded for use under many terms such as 'alternative,' 'complementary', 'holistic' or 'integrative' medical systems [8].

Cichorium intybus was widely distributed in Africa, Asia-temperate, Asia tropical, Europe, Australia, Northern America, and Southern America. The phytochemical screening of $C$. intybus showed the presence of tannins, saponins, flavonoids, terpenoids, cardiac glycosides, and anthocyanins overall plant parts; seeds, leaves, and stem [9]. The C. intybus seeds extract contained appreciable levels of phenolic and flavonoid contents [10]. The flowers of chicory contain saccharides, methoxycoumarin, cichorine, flavonoids, essential oils, and anthocyanins $[11,12]$. Unfortunately, no antimicrobial activity was reported against a wide range of microorganisms by using the hexane extract while; ethyl acetate did [13]. The root and leaf extracts (methanol, distilled water, chloroform, petroleum ether, and acetone) of $C$. intybus were investigated for antibacterial activity against Gram-negative pathogenic bacteria, the extracts showed a wide spectrum of inhibition against the test pathogens. Methanolic extract of the root and leaf proved to have the strongest antibacterial activity [14].

Cinnamomum spp. belong to Lauraceae and had been examined extensively for their essential oil constituents. This genus includes about 250 species in the tropical and subtropical districts, mostly in Asia and some in South and Central America, and Australia [15]. Cinnamomum camphora was known for its medicinal traits in folk medicine. Phytochemical screening showed a presence of alkaloids, Tannins, and carbohydrates, as well as its methanolic extract, presented the maximum antimicrobial activity when compared with the other extracts; chloroform and petroleum ether [16].

Commiphora myrrha belongs to Bruseraceae and it was commonly known as "Myrrh" which is one of the most important medicinal plants. Traditionally, its resin was used in the tackling of wounds, gastrointestinal tract GIT disorders, diarrhea, coughing, thoracic pain [17], gingivitis [18] also, it is very effective in the treatment of urinary tract infection UTI [19].

Foeniculum vulgare Mill is called fennel and belongs to Apiaceae, it features with its aromatic fruits. It was commonly used for the treatment of different disorders as well as it acts as a digestive, carminative, and diuretic agent [20]. Preliminary phytochemical screening confirmed the occurrence of flavonoids, tannins, saponins, steroids, glycosides, terpenoids besides its antimicrobial activity due to its potential essential oil constituents [21] as well as several pharmacological advantages through its bioactive constituents that are very important for human health [22].

Nerium oleander Linn; belongs to Apocynaceae family. It is commonly known as Kaner, an evergreen flowering shrub, and extensively cultivated for its aroma. Its extracts have many pharmacological properties such as a diuretic, expectorant, and sternutatory agent. It is also a highly toxic plant due to the presence of a cardiac toxin hence, it was used topically [23]. Methanolic and water extract of different parts of the plant gave a reasonable activity against some pathogenic microorganisms [24].

Spartium junceum is one of the medicinal plants that belong to the Fabaceae family that was cultivated as ornamental plant [25], its flowers were used for the treatment of gastric ulcers in Turkey [26] it has miscellaneous functions as antioxidant, antifertility, simulator for uterine and GI contraction thus causing vomiting [27-29].

The phenolic compounds could be separated by supercritical fluid extraction apparatus and this technique has been studied extensively 20 years ago [30]. Supercritical fluid extraction had been considered to attain the essential oil from Psidium guajava L. leaves, additionally, the 
non-volatile compounds were attained by $\mathrm{CO}_{2}$ supercritical extraction [31].

The current study aimed to screen the phytochemical composition of all mentioned plants in the review and extraction by a more sophisticated technique known as supercritical fluid extracting equipment SFE under certain conditions and subsequent investigation of the ability of these SFE extracts to inhibit the growth of some pathogenic microorganisms including Gram-positive and Gram-negative bacteria in addition to some pathogenic yeasts and finally, these SFE extracts would be analyzed by gas chromatography to predict their ingredients as an attempt to identify the bioactive components.

\section{Materials and methods}

\section{Plants collected}

Six different plants were collected from the local market and had been finely ground by aggressive blender until turning to a fine powder for easy extraction and further investigations, the following Table 1 includes their scientific, common and Arabic name as well as the parts used for investigations and analyses.

\section{Quantitative assessment for phytochemical constituents}

Ten grams of the air-dried plant powder were extracted independently with $80 \%$ methanol three successive times. The extracts were concentrated, and the dried matter was then dissolved in $50 \mathrm{ml}$ methanol. The alcoholic extracts were then completed to the volume of $100 \mathrm{ml}$ by adding distilled water and used for the following determinations.

\section{Total phenolics}

One $\mathrm{ml}$ of the prepared extract of each specimen was completed to the volume of $10 \mathrm{ml}$ by adding distilled water, then $1 \mathrm{ml}$ of Folin-Ciocalteu reagent was added. The mixture was then shaken vigorously for $5 \mathrm{~min}$, then $10 \mathrm{ml}$ of $70 \% \mathrm{Na}_{2} \mathrm{CO}_{3}$ was added and diluted immediately up to $25 \mathrm{ml}$ by adding distilled water. The latter mixture was incubated for $90 \mathrm{~min}$ at room temperature. The absorbance was measured at $750 \mathrm{~nm}$ against the reagent used as a blank. A standard calibration plot was generated at $750 \mathrm{~nm}$ using known concentrations of gallic acid. The concentrations of phenols in the tested samples were calculated from the calibration plot and expressed as mg gallic acid equivalent of phenol/g of sample [32].

\section{Total flavonoids}

One $\mathrm{ml}$ of the prepared extract of each specimen was completed to the volume of $5 \mathrm{ml}$ by adding distilled water. Immediately $0.3 \mathrm{ml} 5 \% \mathrm{NaNO}_{2}$ was added and the mixture was then left for $5 \mathrm{~min}$. Respectively $0.3 \mathrm{ml}$ $10 \% \mathrm{AlCl}_{3}$ and $2 \mathrm{ml} 1 \mathrm{M} \mathrm{NaOH}$ were added. The mixture was then diluted up to a volume of $10 \mathrm{ml}$ with distilled water and the formed pink color was measured at $550 \mathrm{~nm}$ against the reagent used as a blank. A standard calibration plot was generated at $550 \mathrm{~nm}$ using known concentrations of rutin. The concentrations of flavonoids in the tested samples were calculated from the calibration plot and expressed as mg quercetin equivalent of flavonoids/g of the sample [33].

\section{Total tannins}

The total tannin content in the plant extract was estimated according to Folin-Deins reagent method [34], the absorbance was measured at $755 \mathrm{~nm}$.

\section{Total saponins}

One gram of each plant powder was dispersed in $10 \mathrm{ml}$ of $20 \%$ ethanol. Heating of the over a hot water bath for $4 \mathrm{~h}$ with persistent tilting at about $55^{\circ} \mathrm{C}$. The mixture was filtered, and the residue re-extracted with another $10 \mathrm{ml}$ of $20 \%$ ethanol. The combined extracts were reduced to $2 \mathrm{ml}$ over a water bath at about $90{ }^{\circ} \mathrm{C}$. The concentrate was transferred into a $250 \mathrm{ml}$-separator funnel, and $5 \mathrm{ml}$ of diethyl ether was added and shaken vigorously. The aqueous layer was retrieved whilst the ether layer was thrown away. The purification was done once again then $15 \mathrm{ml}$ of $n$-butanol was added. The merged $n$-butanol extracts were washed twice with $10 \mathrm{ml}$ of $5 \%$ aqueous sodium chloride, then the mixture was heated in a water

Table 1 Data of the plant samples that collected to be analyzed including the scientific, common, Arabic names in addition to the part of interest

\begin{tabular}{lll}
\hline Scientific name & Common name & Arabic name \\
\hline Cichorium intybus & Chicory & Shikoryah-Hindbah \\
Cinnamomum camphora & Camphor & Kafour \\
Commiphora myrrha & Myrrh & Morr \\
Foeniculum vulgare & Fennel & Shamar \\
Nerium oleander & Oleander-Kaner & Resin \\
Spartium junceum & Spanish broom & Seeds \\
\hline
\end{tabular}


bath. After evaporation, the samples were dried in the oven at $65^{\circ} \mathrm{C}$ to a constant weight. The total saponin content was expressed as a percentage [35].

\section{Total alkaloids}

Ten grams of each plant powder was extracted with $90 \%$ ethanol. Mayer's reagent was used according to Woo and Püls [36].

\section{Total soluble carbohydrates}

Extraction According to the described method by Chaplin and Kennedy [37], the plant powder samples were dried at $65^{\circ} \mathrm{C}$ till a constant dry weight and grounded again to a very fine powder by a clean mortar. One gram of the powder was put in a $100 \mathrm{ml}$ conical flask, to which $5 \mathrm{ml}$ of $2 \%$ phenol/water and $10 \mathrm{ml}$ of $30 \%$ trichloroacetic acid were added. The mixture was shaken and kept overnight before being filtered; the filtrate was made up to $50 \mathrm{ml}$.

Estimation Contents of total soluble carbohydrates were determined using anthrone technique [38], the developed color was measured using an electric colorimeter at $620 \mathrm{~nm}$. A blank mixture containing distilled water and reagent was used to set up the apparatus at zero optical densities.

\section{Total water-soluble proteins}

Extraction In this regard, one gram of the oven-dried powder at $60{ }^{\circ} \mathrm{C}$ and then transferred to $250 \mathrm{ml}$ conical flask, then $10 \mathrm{ml}$ distilled water, and $5 \mathrm{ml}$ of $2 \%$ phenol solution were added. The contents of the flasks were shaken well and kept overnight before being filtered, and then they were used for the estimation of soluble proteins.

Determination The optical density of the resulted color was then read at the wavelength of $750 \mathrm{~nm}$. The concentration of soluble protein present in the sample was then calculated making use of the constructed standard curve of proteins [39].

\section{Total nitrogen}

The total nitrogen content of each plant powder was determined according to Kjeldahl digestion [40].

\section{Volatile oil}

Fifty grams of each plant powder was exposed to steam distillation to extract volatile oils according to Balbaa's method [41].

\section{Extraction by supercritical $\mathrm{CO}_{2}$ fluid extractor (SFE)}

Ten grams of each plant powder were used to be extracted via SFE equipment at SFE lab, the regional center for mycology and biotechnology RCMB, Al-Azhar
University. The (Teledyne ISCO SFX 200) includes carbon dioxide injection pumps, extractors, separators, compressors, carbon dioxide tanks, chillers.

The operation of extraction depends upon pushing the $\mathrm{CO}_{2}$ through pipelines to be mixed with the samples under programmed critical conditions which gives $\mathrm{CO}_{2}$ the solvent property, its ability as a tunable solvent differs with changing the critical conditions, these parameters include pressure, temperature, flow rate. In this experiment; the conditions applied were $300 \mathrm{bar}, 55^{\circ} \mathrm{C}$ and $\mathrm{CO}_{2}$ flow rate of $6 \mathrm{~g} / \mathrm{min}$ for $50 \mathrm{~min}$.

\section{In vitro screening of antimicrobial activity of the plant SFE extracts}

Agar well diffusion method described by [42] was applied to determine the antimicrobial activity of six extracts against 10 pathogenic microorganisms; the first four belonged to Gram-positive bacteria, the next four belonged to Gram-negative bacteria and the last two belonged to yeasts, the inoculum of each test organism was prepared according to [43]. This assay was done using gentamycin as a positive control antibacterial and ketoconazole as a positive control antifungal while methanol was selected roughly as a negative control. The medium used for bacterial growth was Mueller-Hinton agar medium (Code; CM0337, Thermo Scientific, Oxoid Microbiology products) which composed of $\mathrm{g} / \mathrm{l}$; beef dehydrated infusion 300, casein hydrolysate 17.5, starch 1.5 and agar 17, this medium is ready to use which had been prepared by weighing $38 \mathrm{~g}$ and up to 11 with distilled water. On the other aspect, yeast was cultivated onto malt extract agar MEA medium (code; CM0059, Thermo Scientific, Oxoid Microbiology products) which composed of (g l); malt extract 30, mycological peptone 5 , agar 15 , this medium is ready to use which had been prepared by weighing $50 \mathrm{~g}$ and up to $1 \mathrm{l}$ with distilled water. The test microorganisms were provided by the lab of antimicrobial and sensitivity assays, the regional center for mycology and biotechnology, Al-Azhar University, Cairo-Egypt, in which this experiment had been done.

\section{Determination of MIC and MBC/MFC for the most active plant extracts}

Depending upon the clear zones diameters resulted by antimicrobial assay, out of the six plant extracts, two only were further investigated to determine their MIC values by which the lowest concentration of plant extract could inhibit the growth on the agar plate, MIC assay was accomplished by diluting the original crude extract (stock) through making these preparations (1:1, $1: 2,1: 3,1: 4,1: 5,1: 6,1: 7)$. By the same protocol of agar well diffusion assay which applied to survey the antimicrobial activities of the six plant extracts, MIC also was 
determined and recorded. Consequently, $\mathrm{MBC}$ by which the minimum bactericidal concentration and MFC by which the minimum fungicidal concentration was determined according to [44] by transferring $10 \mu \mathrm{l}$ from the non-turbid wells to the appropriate broth medium permitting the growth after overnight incubation and finally the turbidity would be determined by a spectrophotometer (UV/visible spectrophotometer; Milton Roy Spectronic 1201) at $530 \mathrm{~nm}$ wavelength according to [45].

\section{GC-MS analysis for prediction of subcomponents}

GC-MS was carried out on Direct Probe Controller Inlet part to Single Quadrupole mass analyzer (Thermo Scientific; GC-MS model ISQ LT) using Thermo X-Caliber software. The Mass spectroscopy system was used to predict the subcomponents of plant SFE extracts using RTX-2330 (fused silica) $30 \mathrm{~m}$ capillary column of $0.25 \mu \mathrm{m}$ internal diameter and $\mathrm{df}(\mu \mathrm{m}) 0.20 \mu \mathrm{m}$. The column was operated at an initial temperature of $160-250^{\circ} \mathrm{C}$ at the rate of $5{ }^{\circ} \mathrm{C} /$ min and was held for $30 \mathrm{~min}$. The injector and detector temperatures were $240{ }^{\circ} \mathrm{C}$ and $250{ }^{\circ} \mathrm{C}$, respectively. The carrier gas (nitrogen) was supplied at a total flow rate of $50 \mathrm{ml} / \mathrm{min}$ with a split ratio of 20:0 and subcomponents were identified by comparison with a linked library.

\section{Results and discussion}

\section{Quantitative phytochemical screening}

The powders of examined plants were processed according to the specific protocols to assess the phytochemical composition belongs to each plant, all the data obtained were tabulated in Table 2 which revealed the concentration of each component.

Regarding total phenolic compounds; F. vulgare has the highest value of $261 \mathrm{mg}$ followed by C. myrrha $247 \mathrm{mg}$, while the lowest value $213 \mathrm{mg}$ belonged to $N$. oleander. In the case of flavonoid concentration; C. myrrha contains the highest value of $159 \mathrm{mg}$ followed by C. intybus $143 \mathrm{mg}$, while the lowest concentration belonged to S. junceum.

Regarding tannins; the uppermost percentage went to C. intybus (4.31\%) followed by C. camphora (4.13\%) while $S$. junceum contains the lowest concentration of tannins $(2.87 \%)$. Referring total saponin values; $F$. vulgare contains the highest percentage $(2.69 \%)$ followed by $N$. oleander $(2.55 \%)$ while the lowest percentage $(2.09 \%)$ belonged to C. camphora.

Concerning alkaloids concentrations, the highest value belonged to C. intybus (3.92\%) followed by both C. camphora and F. vulgare (3.85\%) while the lowest percentage belonged to $S$. junceum (2.87\%).

In the case of total soluble carbohydrates; C. camphora possessed the highest value (3.48\%) followed by C. myrrha (3.07\%) while the lowest carbohydrates content belonged to C. intybus (2.11\%). Regarding soluble proteins and total nitrogen content, the highest value belonged to $C$. intybus ( $15.94 \%$ and $26.76 \%$ respectively) and followed by $F$. vulgare $(13.94 \%$ and $23.41 \%$ respectively) while, the lowest percentage of proteins belonged to $N$. oleander and the lowest nitrogen content belonged to $S$. junceum.

Finally, in the case of oil percentage; the highest concentration was detected in $F$. vulgare $(0.81 \%)$ followed by $N$. oleander $(0.69 \%)$ while, the minimum value was detected in S. junceum (0.41\%).

Regarding phytochemical screening, all examined plant are rich in phenolics, flavonoids, alkaloids, saponins, tannins and this is the reason of their pharmacological properties as good medicinal plants especially, fennel, chicory, and myrrh, this result is in harmony with anthocyanin

Table 2 Phytochemical composition of the six examined plants

\begin{tabular}{|c|c|c|c|c|c|c|}
\hline \multirow[t]{2}{*}{ Item } & \multicolumn{6}{|c|}{ Item concentration for each plant } \\
\hline & $\begin{array}{l}\text { Cichorium } \\
\text { intybus }\end{array}$ & $\begin{array}{l}\text { Cinnamomum } \\
\text { camphora }\end{array}$ & $\begin{array}{l}\text { Commiphora } \\
\text { myrrha }\end{array}$ & $\begin{array}{l}\text { Foeniculum } \\
\text { vulgare }\end{array}$ & Nerium oleander & $\begin{array}{l}\text { Spartium } \\
\text { junceum }\end{array}$ \\
\hline Phenolics (mg EGA) & 237 & 223 & 247 & 261 & 213 & 215 \\
\hline Flavonoids (mg ER) & 143 & 138 & 159 & 131 & 124 & 118 \\
\hline \multicolumn{7}{|l|}{ Conc. $\%$} \\
\hline Tannins & 4.31 & 4.13 & 4.05 & 3.87 & 3.74 & 3.27 \\
\hline Saponins & 2.47 & 2.09 & 2.11 & 2.69 & 2.55 & 2.28 \\
\hline Alkaloids & 3.92 & 3.85 & 3.49 & 3.85 & 2.99 & 2.87 \\
\hline Carbohydrates & 2.15 & 3.48 & 3.07 & 2.21 & 2.86 & 2.94 \\
\hline Proteins & 15.94 & 11.39 & 12.54 & 13.94 & 10.29 & 11.05 \\
\hline Total nitrogen & 26.76 & 21.53 & 21.96 & 23.41 & 21.47 & 20.98 \\
\hline Oils & 0.62 & 0.58 & 0.47 & 0.81 & 0.69 & 0.41 \\
\hline
\end{tabular}

Italic values indicate the highest measurement among all items of the investigated plants

Phenolics were estimated in $\mathrm{mg}$ eq/gallic acid, flavonoids were estimated in $\mathrm{mg}$ eq/rutin while the rest of other items were estimated and expressed as percentages 
that had been from red chicory $C$. intybus in aqueous solution at $\mathrm{pH} 2.5$ [46].

Also, the current results of myrrh are compatible with those who recorded the presence of terpenoids, steroids, tannins, volatile oils, and resins [47].

All data from Table 2 except total phenolics and total flavonoids (only phytochemical constituents that had been expressed in \%) were configured in a stacked column chart (Fig. 1). By the first sight to Fig. 1, it could be noticed that $C$. intybus had the higher content followed by $F$. vulgare, C. myrrha, C. camphora, N. oleander, and the lowest plant content is $S$. junceum.

\section{Supercritical fluid extracting system}

By applying selected parameters, the extraction capacity ranged from 0.4 to $0.6 \mathrm{ml}$ which represents $4-6 \mathrm{wt} \%$ approximately (the original concentration of the stock crude extract). The advantage of using this technique for extraction is a high precision, time-saving, and no

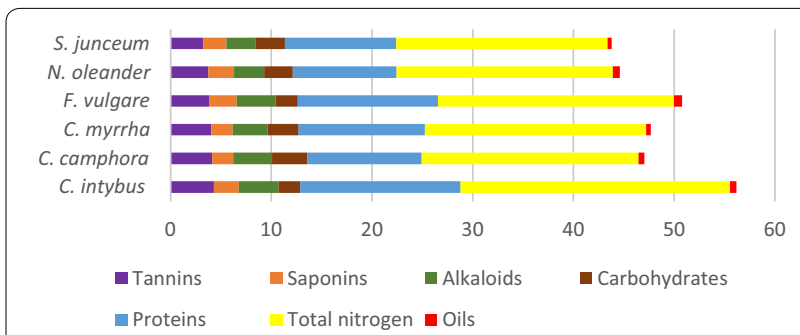

Fig. 1 A stacked column chart expressing the values of phytochemical compounds among all examined plant samples measured in \% solvent traces. This result expressed success of SFE equipment in extraction process; this is friendly with the results reported that the use of SFE in last years had been approved to be alternative for extraction of natural compounds like triterpenes which extracted by both SFE in corresponding to traditional extraction method; Soxhlet and the result of SFE was more satisfying [48]. As well, SFE is a green extraction method providing a concentrated end product with no undesirable residues [49]. The effect of SFE parameters changing to obtain better extractability of phenolic compounds from lavender flowers, different ranges of SFE parameters were checked such as $200 \mathrm{bar}, 40{ }^{\circ} \mathrm{C}$ and $15 \mathrm{~min}$ and the yield was $4.3 \mathrm{wt} \%$ while $250 \mathrm{bar}, 60^{\circ} \mathrm{C}$ for $45 \mathrm{~min}$ gave $9.2 \mathrm{wt} \%$ (more than double) [50].

\section{Antimicrobial activity determination}

Antimicrobial activity of these six different plants was estimated, and the results had been expressed in $\mathrm{mm}$ as diameters of inhibition zones. All the data resulted were tabulated in Table 3 which revealed the following observations:

All test organisms exhibited variation in their responses against the examined crude extracts, Candida albicans exhibited more resistance than $C$. lipolytica among the examined yeast strains; only three extracts had moderate effects against $C$. albicans while all six extracts affected C. lipolytica.

In the case of Gram-positive bacteria; the most resistant strain was $S$. mutans followed by Micrococcus $s p$. and MRSA had been affected only by three extracts

Table 3 Antimicrobial activity of SFE plant extract against some variable pathogenic microorganisms

\begin{tabular}{|c|c|c|c|c|c|c|c|}
\hline Test organism & $\begin{array}{l}\text { Cichorium } \\
\text { intybus }\end{array}$ & $\begin{array}{l}\text { Cinnamomum } \\
\text { camphora }\end{array}$ & $\begin{array}{l}\text { Commiphora } \\
\text { myrrha }\end{array}$ & $\begin{array}{l}\text { Foeniculum } \\
\text { vulgare }\end{array}$ & $\begin{array}{l}\text { Nerium } \\
\text { oleander }\end{array}$ & $\begin{array}{l}\text { Spartium } \\
\text { junceum }\end{array}$ & $\begin{array}{l}\text { Positive } \\
\text { control }\end{array}$ \\
\hline \multicolumn{8}{|l|}{ Pathogenic yeasts Ketoconazol 100 g (positive control) } \\
\hline Candida albicans RCMB 005003 (1) ATCC 10231 & - & 11 & - & 14 & - & 12 & 20 \\
\hline Candida lipolytica RCMB 005004 & 18 & 16 & 17 & 15 & 10 & 8 & 18 \\
\hline \multicolumn{8}{|l|}{ Gram-positive bacteria Gentamycin 4 g (positive control) } \\
\hline MRSA clinical isolate & 11 & - & 7 & 8 & - & - & 30 \\
\hline Enterococcus faecalis ATCC 29212 & 18 & 12 & 13 & 22 & 10 & 13 & 26 \\
\hline Streptococcus mutans RCMB 017 (1) ATCC 25175 & - & - & - & - & - & - & 20 \\
\hline Micrococcus sp. RCMB 028 (1) & - & - & - & - & - & - & 22 \\
\hline \multicolumn{8}{|l|}{ Gram-negative bacteria Gentamycin 4 mg (positive control) } \\
\hline Enterobacter cloaca RCMB 001 (1) ATCC 23355 & - & - & - & - & - & - & 27 \\
\hline Klebsiella pneumonia RCMB 003 (1) ATCC 13883 & - & - & - & - & - & - & - \\
\hline Proteus vulgaris RCMB 004 (1) ATCC 13315 & - & - & 8 & 7 & - & - & 25 \\
\hline Salmonella typhimurium RCMB 006 (1) ATCC 14028 & 14 & 16 & 11 & 20 & - & - & 17 \\
\hline
\end{tabular}

Data expressed as diameters of the inhibition zones in $\mathrm{mm}$ ranged from 7 to $22 \mathrm{~mm}$ for the plant extracts in corresponding to the inhibition zones resulted by positive control which ranged from 17 to $30 \mathrm{~mm}$ 
while E. faecalis was the most susceptible one that had been inhibited by all six investigated extracts.

Referring to Gram-negative bacteria; the most resistant strain was $K$. pneumonia followed by E. cloaca and $P$. vulgaris (only two extracts weakly inhibit its growth) while $S$. typhimurium was the most susceptible one that had been inhibited by four extracts.

On the other side, the investigated crude extracts might be categorized as potent, moderate, and weak antimicrobial agents according to the applied concentrations, also, some of them could be classified as wide spectrum while the others are narrow spectrum. For example; crude extract of $F$. vulgare showed the highest potency against $C$. albicans, E. faecalis, and $S$. typhimurium, it also showed a wide spectrum against seven out of 10. This result is in line with those who had investigated phytochemistry, antimicrobial activity and GC-MS of Portuguese fennel fruits that gave very compatible results with the current study where the crude extract has antimicrobial activity slightly lower than those belonging to the positive standard used; tetracycline as antibacterial and nystatin as antifungal [51]. Also, our finding showed a moderate effect of fennel extract against methicillin-resistant Staphylococcus aureus (MRSA) clinical isolate and this result is relative to those findings which concluded that the combination between fennel essential oil and mupirocin has a significant eradicating effect against $S$. aureus and his finding will be useful antistaphylococcal agent [52].

Extract of $C$. intybus showed a moderate activity especially against $C$. lipolytica and MRSA with moderate range against four out of 10 , while the extract of C. myrrha gave a moderate to weak activity with wide spectrum against six out of 10 . This result in a harmony with hexane and ethyl acetate extracts of chicory roots that showed pronounced antibacterial activity against both Gram-positive and Gram-negative bacteria [53].
SFE extract of C. myrrha has a moderate antimicrobial activity according to the experimental circumstances, it is only active against five out of 10 . This result slightly related to the conclusion related to myrrh extract which has a noticeable antibacterial activity against Enterococcus faecalis and Fusobacterium nucleatum involved in root canal infections especially when it combined with sodium chlorite [54].

Finally, S. junceum and N. oleander could be classified as weak and narrow-spectrum antimicrobial agents; they only active against three and two out of 10 respectively. This finding is consistent with the previously published data that are very limited about antimicrobial activity of Spanish broom. Oleander leaves have antimicrobial activity against Bacillus pumilus, B. subtilis, S. aureus, E. coli, and Aspergillus niger [55].

\section{Determination of MIC and MBC/MFC of the plant extracts}

According to the results of antimicrobial activity assay previously, the crude extracts of both of $C$. intybus and $F$. vulgare were chosen for further investigation for their values of MIC, MBC/MFC. The original concentrations of $C$. intybus and F. vulgare were 5 and $4 \%$ respectively. Different dilutions were prepared and investigated against the indicator strains via agar well diffusion assay, the data resulted was represented in Table 4. The MIC values for C. intybus against Candida lipolytica, MRSA, E. faecalis and Salmonella typhimurium were 1.25, 2.5, 1.67 and $1.67 \%$ respectively, clarifying that the most susceptible test organism is C. lipolytica, and accordingly MBC/MFC was determined, MFC of SFE extract of was $5 \%$ which was the original concentration and it was considered as the minimum fungicidal concentration against $C$. lipolytica, as well the $\mathrm{MBC}$ was $5 \%$ as the minimum bactericidal concentration against $E$. faecalis only, nonetheless the other susceptible bacteria were not completely killed so, the examined concentrations giving the clear zones were considered as bacteriostatic and

Table 4 MIC, MBC/MFC determination for both chicory and fennel extracts

\begin{tabular}{|c|c|c|c|c|c|c|}
\hline \multirow[t]{2}{*}{ Test organism } & \multicolumn{3}{|l|}{ Chicory } & \multicolumn{3}{|l|}{ Fennel } \\
\hline & Stock (mm) & $\begin{array}{l}\text { MIC } \\
\%\end{array}$ & $\begin{array}{l}\text { MBC/MFC } \\
\%\end{array}$ & Stock (IZ) & $\begin{array}{l}\mathrm{MIC} \\
\%\end{array}$ & $\begin{array}{l}\text { MBC/MFC } \\
\%\end{array}$ \\
\hline Candida albicans RCMB 005003 (1) ATCC 10231 & ND & - & - & 14 & 1.33 & ND \\
\hline Candida lipolytica RCMB 005004 & 18 & 1.25 & 5 & 15 & 1.33 & 4 \\
\hline MRSA clinical isolate & 11 & 2.5 & ND & 8 & 4 & ND \\
\hline Enterococcus faecalis ATCC 29212 & 18 & 1.67 & 5 & 22 & 0.8 & 2 \\
\hline Proteus vulgaris RCMB 004 (1) ATCC 13315 & ND & - & - & 7 & 4 & ND \\
\hline Salmonella typhimurium RCMB 006 (1) ATCC 14028 & 14 & 1.67 & ND & 20 & 0.8 & 2 \\
\hline
\end{tabular}

Stock represents the original concentration in corresponding to the inhibition zones diameters expressed in $\mathrm{mm}$, while MIC and MBC/MFC describe the responsible concentration in \% 
these bacteria need a higher concentration to be killed completely.

On the other hand, the MIC values for $F$. vulgare against $C$. albicans, C. lipolytica, MRSA, E. faecalis, Proteus vulgaris and $S$. typhimurium were $1.33,1.33,4,0.8$, 4 and $0.8 \%$ respectively, clarifying that the most susceptible test organisms are E. faecalis and S. typhimurium. Accordingly, MBC/MFC was determined, MFC of SFE extract of was $4 \%$ against $C$. lipolytica, likewise, the MBC was $2 \%$ E. faecalis and S. typhimurium, nevertheless the other susceptible test organisms were not completely killed so, the examined concentrations giving the clear zones were considered as bacteriostatic and these strains need a higher concentration to be killed completely.

The entire results of MIC were in a harmony with [56] who reported variability of MIC values of $C$. intybus extracted by three different solvents against a limited number of test organisms. No much more information about the mechanism of action of antimicrobial agent(s) from $C$. intybus whether bactericidal or bacteriostatic. Regarding $F$. vulgare, the most valuable antimicrobial activity belongs to its essential oil neither alcoholic nor routine extraction methods [57] thus the study attempted to study an unusual method for extraction, and fortunately, it gave reasonable, considerable, valorized results.

\section{Gas chromatographic analyses Cichorium intybus}

There 13 variable compounds were detected in C. intybus by GC-MS analysis (Table 5 and Fig. 2a); most of them belong to fatty acid whether saturated or unsaturated as well as fatty acid precursors. Also, some phenolic and terpenoids were detected. Retinal is also known as retinaldehyde, which is a form of vitamin A produced by oxidation of retinol which functions as the active component of the visual cycle, this compound is unique for chicory.

\section{Cinnamomum camphora}

Table 5 and Fig. $2 \mathrm{~b}$ refer to predict the subcomponents of SFE C. camphora extract that point to the existence of 12 components belong to fatty acids and their precursors in addition to phenolics and terpenoids. Spathulenol is sesquiterpene alcohol as a unique compound for C. camphora during this study. On the other hand, Spirostenone belongs to terpenoids (isoprenoids), this compound found only in both C. intybus and C. camphora.

\section{Commiphora myrrha}

Table 5 and Fig. 2c expressed the prediction of subcomponents of SFE C. myrrha extract, analysis of GC-MS report displayed that 13 compounds had been detected; all these compounds belong to fatty acids and their precursors as well as phenolic and flavonoids.

\section{Foeniculum vulgare}

Foeniculum vulgare SFE extract was analyzed by GCMS (Fig. 2d) to predict its subcomponents which were tabulated in Table 5 which revealed the detection of 15 subcomponents including fatty acids and their precursors. Eugenol and trans isoeugenol are unique for only $F$. vulgare which are classified as phenolic compounds, also squalene is alkene belong to isoprenoid compounds, this compound is also unique for $F$. vulgare.

\section{Nerium oleander}

Nerium oleander SFE extract was examined by GCMS (Fig. 2e) to forecast its ingredients which were presented in Table 5 that shows the presence of 13 kinds of compounds including fatty acids and their precursors. Isofuranodionone is unique for $N$. oleander which is classified as a heterocyclic organic compound.

\section{Spartium junceum}

Only 8 compounds were detected in S. junceum SFE extract and this is the least content diversity among the examined plants, data was obtained by Fig. $2 f$ that represents GC-MS chromatogram of S. junceum SFE extract, subsequently, this figure was analyzed to expect the ingredients which were arranged into Table 5 which showed a limited number and a limited diversity of subcomponents which belong to fatty acid (erucic acid) and precursors of fatty acids. GC-MS analyses for all examined plants showed the presence of fatty acids and fatty acids precursors in all investigated SFE extracts, although some compounds are unique for a specific plant among this study, on the other hands there are some compounds being common between two or more types of the plants under examination, for example; eicosanoic acid is monounsaturated (omega 9) fatty acid and it was detected in C. intybus, C. myrrha, and N. oleander. Erucic acid is also monounsaturated (omega 9) fatty acid and it was detected in C. intybus, C. myrrha, F. vulgare, N. oleander, and $S$. junceum. Doxepin derivative is an antidepressant molecule and it was detected in F. vulgare, $N$. oleander, and $S$. junceum. Spirostenone belongs to terpenoids (isoprenoids), this compound found only in both C. intybus and C. camphora. GC-MS report indicated the presence of residues of solvents involved in the extraction process plus the components constituting ethanolic clove extract [58] but fortunately, in this study, GC-MS report indicated the absence of the residues of solvents as an evidence to the high purity degree of the plant extract yielded by SFE. 
Table 5 GC-MS report of SFE plant extracts exhibiting RT, molecular weight, molecular formula and frequency

\begin{tabular}{|c|c|c|c|c|c|c|c|c|c|c|}
\hline Compound predicted & RT & M. wt & M. formula & 1 & 2 & 3 & 4 & 5 & 6 & $\mathrm{~F}$ \\
\hline Trans isoeugenol & 12.28 & 164 & $\mathrm{C}_{10} \mathrm{H}_{12} \mathrm{O}_{2}$ & & & & O & & & 1 \\
\hline Eugenol & 16.31 & 164 & $\mathrm{C}_{10} \mathrm{H}_{12} \mathrm{O}_{2}$ & & & & O & & & 1 \\
\hline Cyclohexane derivative & 13.13 & 202 & $\mathrm{C}_{15} \mathrm{H}_{24}$ & & & & & O & & 1 \\
\hline Dihydro butyl bezodoxepin & 15.95 & 206 & $\mathrm{C}_{13} \mathrm{H}_{18} \mathrm{O}_{2}$ & & & & $\bullet$ & $\bullet$ & $\bullet$ & 3 \\
\hline Hydroquinone derivative & 15.95 & 206 & $\mathrm{C}_{13} \mathrm{H}_{18} \mathrm{O}_{2}$ & 0 & $\bullet$ & $\bullet$ & & & & 3 \\
\hline Tetradecanol & 17.76 & 214 & $\mathrm{C}_{14} \mathrm{H}_{30} \mathrm{O}$ & 0 & & $\bullet$ & & & & 2 \\
\hline Spathulenol & 17.51 & 220 & $\mathrm{C}_{15} \mathrm{H}_{24} \mathrm{O}$ & & 0 & & & & & 1 \\
\hline Isofuranodionone & 18.11 & 230 & $\mathrm{C}_{15} \mathrm{H}_{18} \mathrm{O}$ & & & & & 0 & & 1 \\
\hline Hexadecanol & 17.76 & 242 & $\mathrm{C}_{16} \mathrm{H}_{34} \mathrm{O}$ & & & 0 & 0 & $\bullet$ & 0 & 4 \\
\hline Tridecanoic acid methyl ester & 20.68 & 256 & $\mathrm{C}_{15} \mathrm{H}_{30} \mathrm{O}_{2}$ & & & & & O & & 1 \\
\hline Tetradecanoic acid methyl ester & 20.68 & 256 & $\mathrm{C}_{16} \mathrm{H}_{32} \mathrm{O}_{2}$ & 0 & & 0 & - & & & 3 \\
\hline Nonadecene & 22.08 & 266 & $\mathrm{C}_{19} \mathrm{H}_{38}$ & & 0 & & & - & 0 & 3 \\
\hline Retinal & 22.82 & 284 & $\mathrm{C}_{20} \mathrm{H}_{28} \mathrm{O}$ & O & & & & & & 1 \\
\hline Hexadecenoic acid methyl ester & 24.76 & 270 & $\mathrm{C}_{17} \mathrm{H}_{34} \mathrm{O}_{2}$ & 0 & 0 & ○ & $\bullet$ & $\bullet$ & $\bullet$ & 6 \\
\hline 9-Eicosene & 26.04 & 280 & $\mathrm{C}_{20} \mathrm{H}_{40}$ & & $\bullet$ & $\bullet$ & & & & 2 \\
\hline Nonadecanoic acid & 27.71 & 296 & $\mathrm{C}_{19} \mathrm{H}_{36} \mathrm{O}_{2}$ & & & & & 0 & & 1 \\
\hline Octadecenoic acid methyl ester & 28.03 & 296 & $\mathrm{C}_{19} \mathrm{H}_{36} \mathrm{O}_{2}$ & ○ & - & ○ & $\bullet$ & $\bullet$ & ○ & 6 \\
\hline 1-Eicosanol & 26.05 & 298 & $\mathrm{C}_{20} \mathrm{H}_{42} \mathrm{O}$ & & & & 0 & & & 1 \\
\hline Heptadecanoic acid ethyl ester & 26.05 & 298 & $\mathrm{C}_{19} \mathrm{H}_{38} \mathrm{O}_{2}$ & O & & & & & & 1 \\
\hline Octadecanoic acid methyl ester & 28.50 & 298 & $\mathrm{C}_{19} \mathrm{H}_{38} \mathrm{O}_{2}$ & & & & & $\bullet$ & $\bullet$ & 2 \\
\hline Methyl stearate & 28.50 & 298 & $\mathrm{C}_{19} \mathrm{H}_{38} \mathrm{O}_{2}$ & & $\bullet$ & 0 & ○ & & & 3 \\
\hline Linoleic acid ethyl ester & 29.11 & 308 & $\mathrm{C}_{20} \mathrm{H}_{36} \mathrm{O}_{2}$ & 0 & & & & & & 1 \\
\hline Eicosenoic acid & 29.21 & 310 & $\mathrm{C}_{20} \mathrm{H}_{38} \mathrm{O}_{2}$ & & & $\bullet$ & & $\bullet$ & & 2 \\
\hline Ethyl oleate & 29.22 & 310 & $\mathrm{C}_{20} \mathrm{H}_{38} \mathrm{O}_{2}$ & 0 & ○ & & ○ & & & 3 \\
\hline Docosene & 29.66 & 308 & $\mathrm{C}_{22} \mathrm{H}_{44}$ & & ○ & - & $\bullet$ & & & 3 \\
\hline Erucic acid & 29.67 & 338 & $\mathrm{C}_{22} \mathrm{H}_{42} \mathrm{O}_{2}$ & 0 & & 0 & - & $\bullet$ & 0 & 5 \\
\hline Eicosenoic acid derivative & 33.96 & 310 & $\mathrm{C}_{20} \mathrm{H}_{38} \mathrm{O}_{2}$ & $\mathrm{O}$ & & & & & & 1 \\
\hline Behenyl alcohol or Doconasol & 33.96 & 326 & $\mathrm{C}_{22} \mathrm{H}_{46} \mathrm{O}$ & & 0 & & & & & 1 \\
\hline Benzene dicarboxylic acid & 38.95 & 390 & $\mathrm{C}_{24} \mathrm{H}_{38} \mathrm{O}_{4}$ & $\bullet$ & $\bullet$ & $\bullet$ & $\bullet$ & $\bullet$ & $\bullet$ & 6 \\
\hline Docosanoic acid trihydroxy methyl ester & 40.26 & 402 & $\mathrm{C}_{23} \mathrm{H}_{46} \mathrm{O}_{5}$ & & & & O & & & 1 \\
\hline Squalene & 44.30 & 410 & $\mathrm{C}_{30} \mathrm{H}_{50}$ & & & & O & & & 1 \\
\hline Spirostenone & 44.29 & 428 & $\mathrm{C}_{27} \mathrm{H}_{40} \mathrm{O}_{4}$ & $\bullet$ & $\bullet$ & & & & & 2 \\
\hline Flavone dioglucoside & 44.30 & 594 & $\mathrm{C}_{27} \mathrm{H}_{30} \mathrm{O}_{15}$ & & & 0 & & & & 1 \\
\hline Total & 33 & 33 & 33 & 13 & 12 & 13 & 15 & 13 & 8 & \\
\hline
\end{tabular}

Numbers (1-6): 1; Chicory, 2; Camphor, 3; Myrrh, 4; Fennel, 5; Oleander, 6; Spanish broom. F means frequency, symbol O means monomorphic peaks while symbol $\bigcirc$ means polymorphic peaks

\section{Conclusion}

Most of the examined plants have medicinal importance especially as antimicrobial activity and those are rich in their phytochemical contents whether alkaloids, flavonoids, etc. which encourages the researchers to investigate more uncommon plants for their medicinal importance, not antimicrobial activities in particular. SFE equipment is an inspiring technique for plant extraction which offers time and effort saving as well as high purity of the crude extract with no organic residues in addition to superior results than the conventional extraction methods. There is a very crucial need for antimicrobial agents to be incorporated more and more into the pharmaceutical market especially those belong to natural sources to overcome the problem of microbial resistance, and the current study presented a primitive inspiring trial to help in complementary and alternative medicine. Also, a combination of those examples of natural antimicrobial agents and other established drugs may offer synergistic powerful effect in tackling the resistance problem. GCMS reports displayed that some examined plants contain very useful unsaturated fatty acids (omega 9) and hence, those antimicrobial extracts may have an additional advantage or a dual-action. 


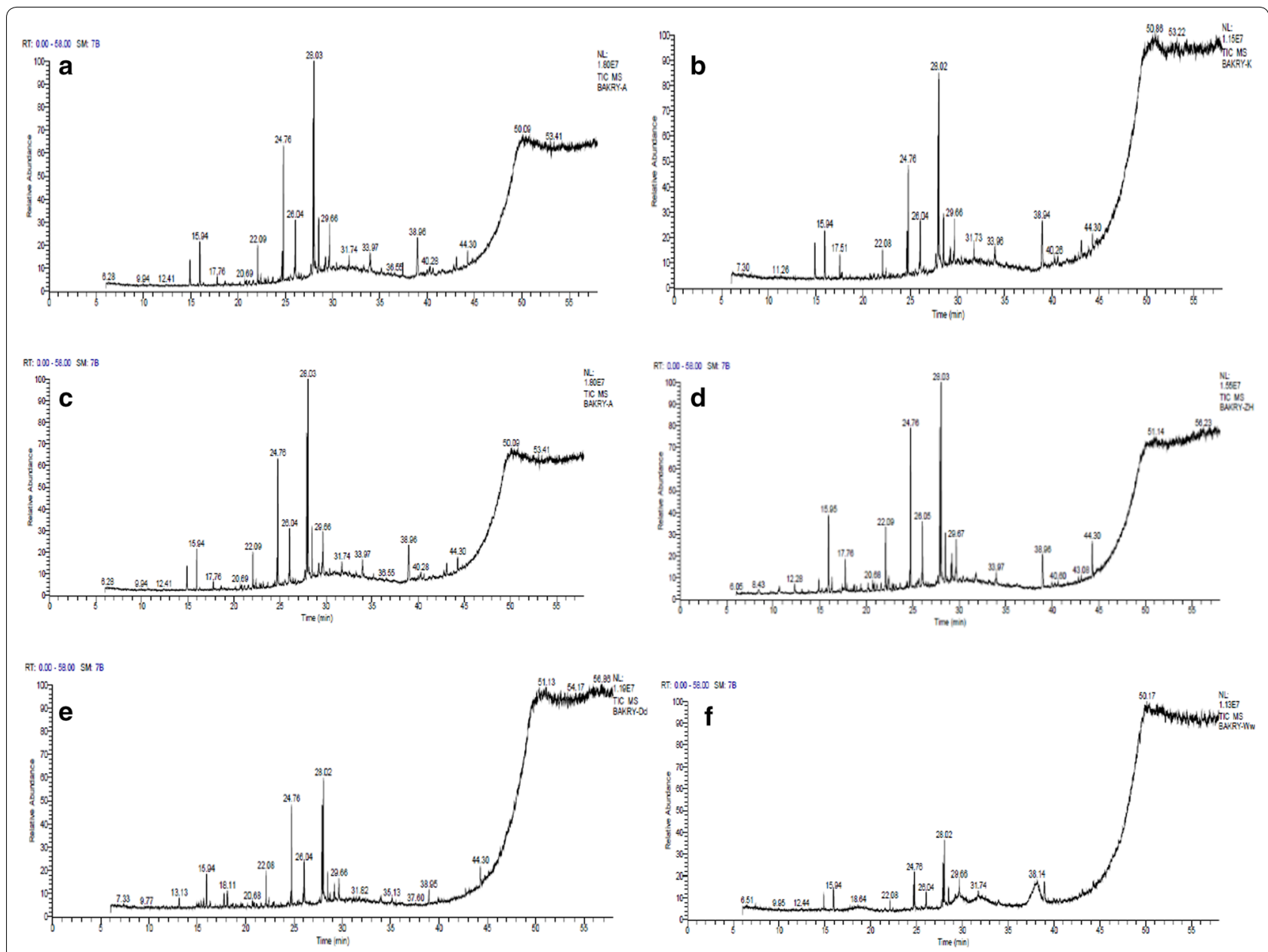

Fig. 2 GC-MS chromatographs of SFE extracts of: a Cichorium intybus b; SFE Cinnamomum camphora c; Commiphora myrrha d; Foeniculum vulgare e; Nerium oleander $\mathbf{f}$; Spartium junceum

\section{Acknowledgements}

The author sincerely thanks the faculty of science as well as the regional center for mycology and biotechnology, Al-Azhar University, Egypt, for providing laboratory facilities.

\section{Authors' contributions}

That all this work was done by himself as a single author without any contribution from any other authors. The author read and approved the final manuscript.

\section{Funding}

That all the experiments and costs are funded personally by himself as a single author; including all analyses, collecting and buying plant samples and there is no competing interest.

\section{Availability of data and materials}

That all data and materials are available and included in the article.

\section{Ethics approval and consent to participate}

That ethics approval is not applicable.

\section{Competing interests}

The author declare no competing interests.

\section{Author details}

${ }^{1}$ Department of Botany and Microbiology, Faculty of Science, Al-Azhar University, The Permanent Camp St., 6th Ward, P.B. 13759, Nasr City, Cairo, Egypt. ${ }^{2}$ Faculty of Advanced Science and Technology, Kumamoto University, Kurokami 2-3-91, Kumamoto 860-8555, Japan.

Received: 28 January 2020 Accepted: 8 July 2020

Published online: 17 July 2020

\section{References}

1. Cheesbrough M. District laboratory practice in tropical countries. Cambridge: Cambridge University Press; 2006.

2. Wilson M, Henderson B, McNab R. Bacterial disease mechanisms: an introduction to cellular microbiology. Cambridge: Cambridge University Press; 2002

\section{Consent to participate}

That consent participates is not applicable. 
3. World Health Organization. The use of essential drugs: ninth report of the WHO expert committee (including the revised Model list of essential drugs). Geneva: World Health Organization; 2000.

4. Suleiman WB. Detection of mecA gene in multidrug resistant Staphylococcus aureus isolated from Egyptian patients. Al-Azhar Bull Sci. 2017;9:357-63.

5. Schulz NS, Canizares CR, Lee JC, Sako M. The ionized stellar wind in vela x-1 during eclipse. Astrophys J Lett. 2001;564(1):L21.

6. Saito H. Regulation of herbal medicines in Japan. Pharmacol Res. 2000:41(5):515-9.

7. Morgan K. Medicine of the gods: basic principles of Ayurvedic medicine Rocester: Charles T. Banford Company; 1994.

8. Tyler VE. Herbal medicine: from the past to the future. Public health Nutr. 2000;3(4a):447-52.

9. Shad M, Nawaz H, Rehman T, Ikram N. Determination of some biochemicals, phytochemicals and antioxidant properties of different parts of Cichorium intybus L.: a comparative study. J Anim Plant Sci. 2013;23(4):1060-6.

10. Mehmood N, Zubair M, Rizwan K, Rasool N, Shahid M, Ahmad VU. Antioxidant, antimicrobial and phytochemical analysis of cichoriumintybus seeds extract and various organic fractions. Iran J Pharm Res IJPR. 2012;11(4):1145

11. Judžentienè A, Būdienè J. Volatile constituents from aerial parts and roots of Cichorium intybus L. (chicory) grown in Lithuania. Chemija. 2008;19(2):25-8.

12. Street RA, Sidana J, Prinsloo G. Cichorium intybus: Traditional uses, phytochemistry, pharmacology, and toxicology. Evid Based Complement Altern Med. 2013;2013:10.

13. Koner A, Ghosh S, Roy P. Isolation of antimicrobial compounds from chicory (Cichorium intybus L.) root. Int J Res Pure Appl Microbiol. 2011;1(2):13-8

14. Verma R, Rawat A, Ganie SA, Agnihotri RK, Sharma R, Mahajan S, Gupta A. In vitro antibacterial activity of Cichorium intybus against some pathogenic bacteria. J Pharm Res Int. 2013;3(4):767-75.

15. Mabberley DJ. Mabberley's plant-book: a portable dictionary of plants, their classification and uses. Cambridge: Cambridge University Press; 2017.

16. Ankita S, Chandra SS, Arti T. Phytochemical study and antimicrobial activities of Cinnamomum camphora. World J Pharm Res. 2013;3:2287-94.

17. Ghazanfar SA. Handbook of Arabian medicinal plants. Boca Raton: CRC Press; 1994.

18. Serfaty $\mathrm{R}$, Itic J. Comparative clinical trial with natural herbal mouthwash versus chlorhexidine in gingivitis. J Clin Dentist. 1988;1:A34-7.

19. Wojtyczka RD, Kępa M, Idzik D, Kubina R, Kabała-Dzik A, Dziedzic A, Wąsik TJ. In vitro antimicrobial activity of ethanolic extract of Polish propolis against biofilm forming Staphylococcus epidermidis strains. Evid Based Complement Altern Med. 2013;2013:11.

20. Saviuc C, Marinas I, Grumezescu AM, Bleotu C, Chifiriuc C, Mihaiescu D, Lazar V. Phytochemical composition of the fennel fruits essential oil and its influence on prokariotic cells growth and pathogenic features. Biointerface Res Appl Chem. 2012;2(2):300-5.

21. Purkayastha S, Narain R, Dahiya P. Evaluation of antimicrobial and phytochemical screening of Fennel, Juniper and Kalonji essential oils against multi drug resistant clinical isolates. Asian Pac J Trop Biomed. 2012;2(3):S1625-9.

22. Kooti W, Moradi M-T, Ali-Akbari S, Sharafi-Ahvazi N, Asadi-Samani M, Ashtary-Larky D. Therapeutic and pharmacological potential of Foeniculum vulgare Mill: a review. J HerbMed Pharmacol. 2014;4:1-9.

23. Rajendran A. Isolation, characterization, pharmacological and corrosion inhibition studies of flavonoids obtained from Nerium oleander and Tecoma stans. Int J PharmTech Res. 2011;3(2):1005-13.

24. Fartyal M, Kumar P. Bioactivity of crude extracts of Nerium oleander Linn. extracted in polar and non polar solvents. J Sci Innov Res. 2014;3(4):426-32.

25. Nadaf M, Halimi M, Mortazavi M. Identification of nonpolar chemical composition Spartium junceum flower growing in Iran by GC-MS. MiddleEast J Sci Res. 2012;11(2):221-4.

26. Yeşilada E, Takaishi Y, Fujita T, Sezik E. Anti-ulcerogenic effects of Spartium junceum flowers on in vivo test models in rats. J Ethnopharmacol. 2000;70(3):219-26.
27. Toker G, Aslan M, Yeşilada E, Memişoğlu M, Ito S. Comparative evaluation of the flavonoid content in officinal Tiliae flos and Turkish lime species for quality assessment. J Pharm Biomed Anal. 2001;26(1):111-21.

28. Baccetti B, Burrini AG, Chen JS, Collodel G, Giachetti D, Matteucci F, Menesini-Chen M, Moretti E, Piomboni P, Sensini C. Evaluation of the antifertility activity of the broom Spartium junceum in the mammalian male. Zygote. 1993;1 (1):71-8.

29. Menghini L, Massarelli P, Bruni G, Pagiotti R. Anti-inflammatory and analgesic effects of Spartium junceum L. flower extracts: a preliminary study. J Med Food. 2006;9(3):386-90.

30. Tyśkiewicz K, Konkol M, Rój E. The application of supercritical fluid extraction in phenolic compounds isolation from natural plant materials. Molecules. 2018;23(10):2625.

31. da Silva CG, Lucas AM, Santo ATDE, Almeida RN, Cassel E, Vargas RM. Sequential processing of Psidium guajava L leaves: steam distillation and supercritical fluid extraction. Braz J Chem Eng. 2019;36(1):487-96.

32. Maurya S, Singh D. Quantitative analysis of total phenolic content in Adhatoda vasica Nees extracts. Int J PharmTech Res. 2010;2(4):2403-6.

33. Rohman A, Riyanto S, Yuniarti N, Saputra W, Utami R, Mulatsih W. Antioxidant activity, total phenolic, and total flavaonoid of extracts and fractions of red fruit (Pandanus conoideus Lam). Int Food Res J. 2010;17(1):97-106.

34. Polshettiwar S, Ganjiwale R, Wadher S, Yeole P. Spectrophotometric estimation of total tannins in some ayurvedic eye drops. Indian J Pharm Sci. 2007:69(4):574.

35. Obadoni B, Ochuko P. Phytochemical studies and comparative efficacy of the crude extracts of some haemostatic plants in Edo and Delta States of Nigeria. Glob J Pure Appl Sci. 2002;8(2):203-8.

36. Woo C, Püls M. The Peierls mechanism in MgO. Phil Mag. 1977:35(6):1641-52

37. Chaplin MF, Kennedy JF. Carbohydrate analysis: a practical approach. 2nd ed. Oxford: IRL Press Ltd; 1994

38. Somogyi M, Nelson N, Hodge J, Hofreiter B. Determination of reducing sugars and carbohydrates. Methods Carbohydr Chem. 1962;1:380-94.

39. Lowry OH, Rosebrough NJ, Farr AL, Randall RJ. Protein measurement with the Folin phenol reagent. J Biol Chem. 1951;193(1):265-75.

40. Adegunwa M, Adebowale A, Solano E. Effect of thermal processing on the biochemical composition, antinutritional factors and functional properties of beniseed (Sesamum indicum) flour. Am J Biochem Mol Biol. 2012;2(3):175-82.

41. Balbaa S, Hilal S, Haggag M. The volatile oil from the herb and fruits of Carum copticum at different stages of growth. Planta Med. 1973;23(04):312-20

42. Hou L, Shi Y, Zhai P, Le G. Antibacterial activity and in vitro anti-tumor activity of the extract of the larvae of the housefly (Musca domestica). J Ethnopharmacol. 2007;111(2):227-31.

43. Microbiology ECfASTotESOC, Diseases I. Determination of minimum inhibitory concentrations (MICs) of antibacterial agents by agar dilution. Clin Microbiol Infect. 2000;6(9):509-15.

44. Sudjana AN, D'Orazio C, Ryan V, Rasool N, Ng J, Islam N, Riley TV, Hammer KA. Antimicrobial activity of commercial Olea europaea (olive) leaf extract. Int J Antimicrob Agents. 2009;33(5):461-3.

45. Vieira D, Fiuza TF, Salgado H. Development and validation of a rapid turbidimetric assay to determine the potency of cefuroxime sodium in powder for dissolution for injection. Pathogens. 2014;3(3):656-66.

46. Migliorini AA, Piroski CS, Daniel TG, Cruz TM, Escher GB, Vieira do Carmo MA, Azevedo L, Marques MB, Granato D, Rosso ND. Red chicory (Cichorium intybus) extract rich in anthocyanins: chemical stability, antioxidant activity, and antiproliferative activity in vitro. J Food Sci. 2019;84(5):990-1001.

47. Alhussaini MS, Saadabi A, Alghonaim MI, Ibrahim KE. An evaluation of the Antimicrobial activity of Commiphora myrrha Nees (Engl.) oleo-gum resins from Saudi Arabia. J Med Sci. 2015;15(4):198.

48. Kristó T, Terdy P, Simandi B, Szöke E, Lemberkovics E, Kery A. Efficiency of supercritical fluid extraction for the production of non-volatile terpenoids from Taraxaci radix. Acta Pharm Hung. 2001;71(3):318-24.

49. Sánchez-Camargo AdP, Parada-Alonso F, Ibáñez E, Cifuentes A. Recent applications of on-line supercritical fluid extraction coupled to advanced analytical techniques for compounds extraction and identification. J Sep Sci. 2019;42(1):243-57.

50. Tyśkiewicz K, Konkol M, Rój E. Supercritical carbon dioxide $\left(\mathrm{scCO}_{2}\right)$ extraction of phenolic compounds from lavender (Lavandula 
angustifolia) flowers: a box-behnken experimental optimization. Molecules. 2019;24(18):3354.

51. Mota AS, Martins MR, Arantes S, Lopes VR, Bettencourt E, Pombal S, Gomes AC, Silva LA. Antimicrobial activity and chemical composition of the essential oils of Portuguese Foeniculum vulgare fruits. Natural product communications. 2015;10(4):1934578X1501000437.

52. Kwiatkowski P, Pruss A, Masiuk H, Mnichowska-Polanowska M, Kaczmarek M, Giedrys-Kalemba S, Dołęgowska B, Zielińska-Bliźniewska H, Olszewski $J$, Sienkiewicz M. The effect of fennel essential oil and trans-anethole on antibacterial activity of mupirocin against Staphylococcus aureus isolated from asymptomatic carriers. Adv Dermatol Allergol Postępy Dermatologii i Alergologii. 2019;36(3):308.

53. Nandagopal S, Kumari BR. Phytochemical and antibacterial studies of Chicory (Cichorium intybus L.) —a multipurpose medicinal plant. Adv Biol Res. 2007;1(1-2):17-21.

54. Al-Madi EM, Almohaimede AA, Al-Obaida MI, Awaad AS. Comparison of the Antibacterial Efficacy of Commiphora molmol and sodium hypochlorite as root canal irrigants against Enterococcus faecalis and Fusobacterium nucleatum. Evid Based Complement Altern Med. 2019;2019:6916795.

55. Hussain M, Gorsi M. Antimicrobial activity of Nerium oleander Linn. Asian Journal of Plant Sciences. 2004;3(2):177-80.

56. Rub RA, Sasikumar S. Antimicrobial screening of Cichorium intybus seed extracts. Arab J Chem. 2016:9:S1569-73.

57. Al-Hadid KJ. Quantitative analysis of antimicrobial activity of'Foeniculum vulgare: a review. Plant Omics. 2017;10(1):28.

58. Suleiman WB, Ibrahim M, El Baz H. In vitro evaluation of Syzygium aromaticum L. ethanol extract as biocontrol agent against postharvest tomato and potato diseases. Egypt J Bot. 2019;59(1):81-94.

\section{Publisher's Note}

Springer Nature remains neutral with regard to jurisdictional claims in published maps and institutional affiliations.
Ready to submit your research? Choose BMC and benefit from:

- fast, convenient online submission

- thorough peer review by experienced researchers in your field

- rapid publication on acceptance

- support for research data, including large and complex data types

- gold Open Access which fosters wider collaboration and increased citations

- maximum visibility for your research: over $100 \mathrm{M}$ website views per year

At BMC, research is always in progress.

Learn more biomedcentral.com/submissions 